\title{
Factor structure of the Cybersex Motives Questionnaire
}

\author{
ELISABETH FRANC ${ }^{1}$, YASSER KHAZAAL ${ }^{1,2,3 *}$, KATARZYNA JASIOWKA $^{2}$, THIBAULT LEPERS ${ }^{2}$, \\ FRANCESCO BIANCHI-DEMICHELI ${ }^{1,2}$ and STÉPHANE ROTHEN ${ }^{1,2}$ \\ ${ }^{1}$ Department of Psychiatry, University of Geneva, Geneva, Switzerland \\ ${ }^{2}$ Department of Mental Health and Psychiatry, Geneva University Hospital, Geneva, Switzerland \\ ${ }^{3}$ Research Centre, University Institute of Mental Health at Montreal, Montreal, Canada
}

(Received: July 27, 2017; revised manuscript received: March 31, 2018; second revised manuscript received: June 17, 2018; accepted: July 28, 2018)

\begin{abstract}
Background and aims: The Internet is widely used for sexual activities and pornography. Little is known, however, about why people look for meetings and sexual interactions through the Internet and about the correlates of cybersex addiction. The goal of this study was to construct a questionnaire for cybersex motives [Cybersex Motives Questionnaire (CysexMQ)] by adapting the Gambling Motives Questionnaire to cybersex use and validating its structure. Methods: Two online samples of 191 and 204 cybersex users were collected to conduct a principal component analysis (PCA) on the first sample and a confirmatory factor analysis (CFA) on the second. Cronbach's $\alpha$ and composite reliability were computed to assess internal consistency. Correlations between the CysexMQ and the Sexual Desire Inventory (SDI) were also evaluated. Results: Two competing models were retained from the PCA, one with two factors and the other with three factors. The CFA showed better fit for the three-factor solution. After three cross-loading items were removed, the results showed that a final 14-item three-factor solution (enhancement, coping, and social motives) was valid (adjusted goodness-of-fit index: 0.993; normed-fit index: 0.978; Tucker-Lewis index: 0.985; comparative fit index: 0.988; root mean square error of approximation: 0.076). Positive correlations were found between the different motives and the subscales of the SDI. Discussion: The results suggest that the CysexMQ is adequate for the assessment of cybersex motives.
\end{abstract}

Keywords: cybersex, motives, pornography, Internet addiction, Gambling Motives Questionnaire

\section{INTRODUCTION}

The significant expansion of the Internet in recent decades and its widespread use in everyday life in most societies has raised debate in the scientific community. Although the Internet might be considered a powerful tool that provides access to a wide variety of information and therefore aids globalization, it has also quickly become a kind of refuge where people's fantasies flourish without real-life consequences and where some people with important health issues get lost in its depths. Only a few studies have focused on one particular use of the Internet that has succeeded from the beginning and continually grown in popularity: cybersex (Gmeiner, Price, \& Worley, 2015). Cybersex can be defined as the use of online sexual activities, such as pornography, live sex shows, webcams, or chat rooms. It has been argued that everything that can be done sexually in real life can be done on the Internet (Carnes, 2001).

The Internet is commonly used for sexual activities (Grubbs, Volk, Exline, \& Pargament, 2015), the close link between the two having developed pervasively. The accessibility, affordability, and anonymity of the Internet encourage repeated sexual interactions and disempowerment owing to the illusive appearance of such behind-the-screen interactions, wherein the virtual world seems less real. People more easily allow personal fantasies when they cannot affect someone physically, leading to a pernicious feeling of safety and disinhibition (Young, Griffin-Shelley, Cooper, O'mara, \& Buchanan, 2000).

Although several users have reported a positive impact of cybersex (Grov, Gillespie, Royce, \& Lever, 2011), some have perceived themselves as having an addictive use of cybersex products (Bothe et al., 2018; Grubbs et al., 2015; Kor et al., 2014). Internet addiction related to sexual content seems to affect a small but significant proportion of the Internet-using population (Dufour et al., 2016; Frangos, Frangos, \& Sotiropoulos, 2011; Grubbs et al., 2015; Kafka, 2010; Ross, Mansson, \& Daneback, 2012). Negative consequences of excessive cybersex, also designated as cybersex addiction, are associated with psychological distress and disturbances in sleep and day-to-day life responsibilities, or with psychosocial dysfunction (Grubbs et al., 2015; Tsimtsiou et al., 2014; Twohig, Crosby, \& Cox, 2009). Because motives are known to be of great * Corresponding author: Yasser Khazaal; Geneva University Hos-
pital, Grand-Pré 70C, Geneva 1206, Switzerland; Phone: +41 22372
55 50; Fax: +41 2232028 40; E-mail: yasser.khazaal@hcuge.ch

This is an open-access article distributed under the terms of the Creative Commons Attribution-NonCommercial 4.0 International License, which permits unrestricted use, distribution, and reproduction in any medium for non-commercial purposes, provided the original author and source are credited, a link to the CC License is provided, and changes - if any - are indicated. 
influence in behavioral addictions (Billieux et al., 2011; Clarke et al., 2007; Hilgard, Engelhardt, \& Bartholow, 2013; Kiraly et al., 2015; Kuss, Louws, \& Wiers, 2012; Zanetta Dauriat et al., 2011), the main goal of this study was to assess cybersex motives and to validate the Cybersex Motives Questionnaire (CysexMQ).

Although the topic of cybersex addiction is likely of clinical importance, it has rarely been studied (Brand et al., 2011; Doring, 2009). Little is known about why people look for meetings and sexual interactions through the Internet and about the correlates of cybersex addiction (Kafka, 2010). The expectation of sexual arousal and pleasure has been hypothesized to be a key motive for cybersex and may have a role in cybersex addiction (Young, 2008). Accordingly, several studies have shown that, compared with controls, people classified as having cybersex addiction reported having greater cue reactivity and sexual arousal from pornographic cue presentation (Laier, Pawlikowski, Pekal, Schulte, \& Brand, 2013).

In particular, some studies found that negative consequences of cybersex use (i.e., addictive use) are associated with perceived sexual arousal when individuals view Internet pornographic material (Brand et al., 2011). Furthermore, such addictive use was associated with higher activation of neural regions associated with drug-cue reactivity, such as the dorsal anterior cingulate, ventral striatum, and amygdala (Voon et al., 2014). As expected, relative to healthy controls, people with cybersex addiction had greater desire but similar liking scores in response to sexually explicit video cues (Voon et al., 2014). Such results are in accordance with models suggesting that in addictive behaviors, "wanting" becomes dissociated from "liking" (Robinson \& Berridge, 2008).

As reported in research on other behavioral addictions (Billieux et al., 2013; Khazaal et al., 2015; Zanetta Dauriat et al., 2011), cybersex addiction is mediated by coping (i.e., escape from real-life problems using pornography) through the use of online sexually related materials (Laier \& Brand, 2014). For instance, the Hypersexual Behavioral Inventory, a self-reported questionnaire that assesses excessive and problematic use of sex in general, includes three subscales: one related to control, one to consequences, and one to coping (the use of sex to cope with aversive affective states or in response to stress; Reid, Li, Gilliland, Stein, \& Fong, 2011). The Pornography Consumption Inventory (Reid et al., 2011) assesses motivations for using pornography with a 15-item self-reported questionnaire related to the following dimensions: emotional avoidance (i.e., coping), sexual curiosity, excitement seeking, and pleasure.

Despite the small number of studies in the field, published articles suggest that the two probable motives linked to cybersex addiction to cope with aversive emotions and real-life problems are sexual gratification and the use of Internet-related sexual activities (Laier \& Brand, 2014). Unsurprisingly, as described in studies related to other behavioral addictions on the Internet (Carli et al., 2013; Geisel, Panneck, Stickel, Schneider, \& Muller, 2015; Khazaal et al., 2012), cybersex addiction was found to be associated with psychological symptoms and distress; it was not, however, associated with offline sexual behaviors (Brand et al., 2011; Laier, Pekal, \& Brand, 2015).
Previous theories and research in the field of cybersex addiction have mostly investigated on how the process and its consequences evolve, but a definition is lacking about the motivations driving such behaviors. In fact, motivations leading to addictive behaviors were first investigated in the field of alcohol-use disorders (Cooper, Russell, Skinner, \& Windle, 1992), in which drinking motives were considered to involve a three-factor model: enhancement, social, and coping. Enhancement expresses an internal and positive reinforcement to raise positive emotions. The social factor refers to the external and positive reinforcement to increase social affiliation. Coping represents all of the internal strategies implemented by the individual to reduce negative effects.

It seems legitimate to doubt that the factors associated with drinking motives apply to an addiction without an intoxicating substance, such as gambling or cybersex. However, these factors have been demonstrated to be relevant for gambling motives, for example, in a study conducted by Stewart and Zack (2008). They validated the three-factor structure of the Gambling Motives Questionnaire (GMQ) on the basis of the same construct of 15 items with five items per factor. Further studies validated a modified version of the GMQ, including monetary motives as an additional drive specifically related to gambling (Dechant \& Ellery, 2011). These findings suggest that the GMQ can be set in the context of the motives it is supposed to measure. It also shows that the questionnaire is plastic and that modifying its construct may be fruitful for assessing cybersex motives.

According to previous studies on cybersex addiction, specifically on the use of pornography (Brand et al., 2011; Laier \& Brand, 2014; Laier et al., 2015; Reid et al., 2011), it is plausible to hypothesize that the GMQ and its related factors, enhancement (a gratification-like motive) and coping, may be involved in cybersex motives.

It also makes sense to consider the involvement of the social motive in cybersex behavior. For instance, studies on online dating highlighted the importance of motives related to socializing for romantic or casual sex purposes (Sumter, Vandenbosch, \& Ligtenberg, 2017). The three-factor model of the GMQ adapted from the Drinking Motives Questionnaire thus seems relevant for cybersex motivations. First, the enhancement factor as a cybersex motive would capture the fact that users frequently report feeling excited, attractive, uninhibited, and thrilled when online (Young, 2008). Second, cybersex users explore a new social world, where the cyberspace culture offers encouragement and acceptance of even their deepest fantasies on the hazardous route to social affiliation (Young, 2008), which illustrates the relevance of the social factor in cybersex motives. Third, the coping dimension could apply to cybersex motives, given that cybersex users often relate that they experience a breach with reality followed by oblivion to real-life concerns when engaged in cybersex activities (Laier \& Brand, 2014).

Cybersex activities differ, however, from gambling activities. For instance, motives assessed with GMQ items, such as "It is something to do on a special occasion" or "It's what most of your friends do when you get together," do not appear to be appropriate for cybersex assessment. Furthermore, specific cybersex motives (i.e., masturbation) were not evaluated with the GMQ. A specific CysexMQ is thus needed. 
The aim of this study was to investigate and validate the factor structure of the motives for cybersex in an adapted version of the GMQ: the CysexMQ.

\section{METHODS}

\section{Participants}

Recruitment was carried out through advertisements posted on specialized forums and websites. Inclusion criteria were being 18 years and older and a user of websites with sexrelated content.

Two distinct samples were recruited. Among the 774 subjects who clicked on the link to the study, 640 of them gave their consent to participate. After removing cases with missing values on the GMQ, we included 395 subjects in the analyses. In Sample $1(n=191), 137(71.7 \%)$ were males. The age range was between 18 and 69 years, with a median of 32. Males were older than females (median age of males: 34; median age of females: 27; Wilcoxon test: $W=3,247 ; p<.05)$. Seventy-six subjects $(39.8 \%)$ were single, $72(37.7 \%)$ were in a relationship, $42(22.0 \%)$ were married, and 1 was widowed. Regarding sexual orientation, $145(77.5 \%)$ declared themselves to be heterosexual, $11(5.9 \%)$ to be homosexual, and $31(16.6 \%)$ to be bisexual. In Sample $2(n=204), 76$ subjects $(37.6 \%)$ were males. The age range was between 18 and 58 years, with a median of 31. Males were younger than females (median age of males: 29; median age of females: 32.5; Wilcoxon test: $W=3,790$; $p<.05)$. Forty subjects $(19.7 \%)$ were single, $107(52.7 \%)$ were in a relationship, $54(26.6 \%)$ were married, and 2 were widowed. Regarding sexual orientation, 172 (84.7\%) declared themselves to be heterosexual, $8(3.9 \%)$ to be homosexual, and $23(11.3 \%)$ to be bisexual.

\section{Measurements}

All participants first filled out a general questionnaire on their personal data (sex, age, nationality, sexual orientation, etc.) and a 24-item form about their experience with the Internet and sexuality (time spent online on sexual websites, satisfaction with meetings on the Internet, frequency of sexual activity during the last month, etc.).

Gathering of demographic and specific information was followed by completion of different self-rating questionnaires: the Sexual Desire Inventory (SDI) and the CysexMQ. The SDI (Spector, Carey, \& Steinberg, 1996) is one of the most commonly used instruments for assessing sexual desire (Mark, Toland, Rosenkrantz, Brown-Stein, \& Hong, 2018). The scale was developed in English and validated in different languages (King \& Allgeier, 2000; Moyano, Vallejo-Medina, \& Sierra, 2017; Ortega, Zubeidat, \& Sierra, 2006; Spector et al., 1996). The psychometric characteristics of the SDI were also assessed among people with different sexual orientations, including lesbians and gay males (Mark et al., 2018).

The SDI was developed to assess the cognitive component of sexual desire. The instrument involves two dimensions: dyadic sexual desire (interest in sexual activity with a partner) and solitary sexual desire (interest in engaging in sexual behavior by oneself). The solitary dimension is associated with the frequency of solitary sexual behavior, whereas the dyadic dimension is associated with the frequency of sexual activities with a partner (Spector et al., 1996). Good test-retest reliability (Spector et al., 1996) has been reported, as well as convergent validity with other measures of sexual desire and with sexual satisfaction (Mark et al., 2018).

The CysexMQ is a self-assessment scale (Supplementary Material) that is rated on a 5-point Likert scale from 1 (never) to 5 (always or almost always).

The authors modified items on the social motives subscale of the GMQ to better fit with cybersex activities. For example, the motives "As a way to celebrate," "It's what most of your friends do when they get together," and "It's something you do on special occasions" were removed. Other types of social motives such as "To meet somebody" and "Because I need to exchange with other people" were added. The motive "To be sociable" was modified to "For being sociable and appreciated by others." For the GMQ enhancement motive, the item "To win money" was replaced by "To get entertained." Other specific motives added related to cybersex activities were "For masturbation" and "For watching." Items were generated via indepth clinical interviews of patients regarding their motives related to cybersex use. These patients were consulting for addictive cybersex in the addiction facility of the Department of Mental Health and Psychiatry of the Geneva University Hospital. After several discussions with clinicians and between authors, the second, fourth, and fifth authors conducted thematic analyses of these qualitative responses. The items were then generated according to the principles of item generation (i.e., addressing a single issue, simple and short statements; Harrison \& McLaughlin, 1993) and discussed until a consensus was reached among the authors.

The main outcome measure of this study was the CysexMQ.

\section{Data analysis}

Despite the fact that a three-factor structure was expected, an exploratory analysis was first performed instead of a confirmatory analysis in order to allow a specific structure to emerge in this new framework. To achieve this goal, we performed a principal component analysis (PCA) followed by a varimax rotation on the original sample of 191 . With the discrete nature of the GMQ items, a PCA is preferred over an exploratory factor analysis, because it does not assume any particular multivariate model, which is not the case for an exploratory analysis (Schneeweiss \& Mathes, 1995). Moreover, when the same numbers of factors or components are extracted, both techniques yield highly similar results (Velicer \& Jackson, 1990). The number of components to extract was determined by the scree test (Cattell, 1966), and Velicer's (1976) minimum average partial (MAP) test was carried out on the correlation matrix. The MAP test was bootstrapped.

In a second step, we recruited a second sample of 204 in order to run a confirmatory factor analysis (CFA). Because of the discrete nature of the CysexMQ items, the unweighted 
least squares (ULS) with robust standard errors (Li, 2016) method was chosen as the procedure for estimation.

Five preestablished criteria were selected as indicators of the goodness of fit to the data: (a) adjusted goodness-of-fit index (AGFI) $>0.80 \quad$ (Joreskog \& Sorbom, 1996); (b) normed-fit index (NFI) $>0.90$ (Bentler \& Bonnet, 1980); (c) Tucker-Lewis index (TLI) $>0.95$ (Tucker \& Lewis, 1973); (d) comparative fit index (CFI) $>0.95$ (Bentler, 1990); and (e) root mean square error of approximation (RMSEA) <0.06 (Hu \& Bentler, 1999). The use and cutoff of the AGFI was recommended by Cole (1987), of the NFI by Bentler and Bonnet (1980), and of the RMSEA, TLI, and CFI by $\mathrm{Hu}$ and Bentler (1999).

The reliability of the questionnaire was assessed using the Cronbach's $\alpha$ coefficient (Cronbach \& Meehl, 1985) and composite reliability (CR), which are measures of internal consistency. In order to assess convergent validity, we calculated Spearman's correlations between the dyadic and solitary SDI subscales and the CysexMQ subscales. The PCA, CFA, and bootstrap were performed with R version 3.1.3, using the psych (Revelle, 2014), bootstrap (Kostyshak, 2015), and lavaan (Rosseel, 2012) packages.

\section{Ethics}

The study procedures were carried out in accordance with the Declaration of Helsinki. The ethical committee of the Geneva University Hospital gave approval for the study protocol. Participants were given detailed descriptions of the objectives and methods of the study. Following online informed consent, participants completed the questionnaires anonymously online via SurveyMonkey links.

\section{RESULTS}

\section{Results from the PCA}

Number of factors retained. The scree test (Figure S1 of Supplementary Material) clearly suggested retaining three factors, whereas the MAP test (Figure S2 of Supplementary Material) gave an ambiguous solution because either two or three factors had close values $(0.0301$ and 0.0302 , respectively), knowing that the MAP test interpretation being done on the basis of the smaller the better. To disentangle the MAP test result, we applied a bootstrap technique (Efron, 1987), which confirmed the ambiguity. Among the 1,000 bootstrap samples, $52 \%$ suggested retaining two factors and
$43 \%$ suggested retaining three factors; the boxplots from the bootstrapped MAP test (Figure S3 of Supplementary Material) for two and three factors overlapped almost completely.

Factor loadings. Three items were problematic within the three-factor solution, because they had loadings greater than 0.40 on more than one component: Items 2 and 17 on Factors I and II, respectively, and Item 16 on Factors II and III. The two-factor solution contained the smallest loading, with 0.37 on Item 13 ("For feeling confident about myself and upgrading my self-esteem"). Items 12, 15, and 17 were also problematic, because they had loadings greater than 0.40 on both components. The explained variance was about 0.47 for the two-factor solution and 0.55 for the three-factor solution. Factor loadings are shown in Tables S1 and S2 of the Supplementary Material.

A cross-loading was observed on enhancement and coping for Item 2 ("To relax") and Item 17 ("Because it makes me feel good"). A different cross-loading on coping and social factors was observed for Item 16 ("For feeling confident about myself and upgrading my self-esteem").

Because of the similarity in the cross-loading of Items 2 and 17, we decided to first test a model without these items (3F-a; Table 1), conserving, however, Item 16 related to cybersex use for self-esteem motives. Then, we tested a model without the three items concerned by cross-loading (3F-b; Table 1).

\section{Results from the CFA}

In order to decide whether it is better to retain two or three factors, we first compared both models. The first part of Table 1 shows the fit indices of the two-factor and the threefactor solutions. Both models yielded excellent fit, except for the RMSEA, which is slightly larger than the cutoff of 0.06 . The three-factor solution shows the best fit everywhere. Since fit indices were very close to each other for the two models, we compared them statistically, knowing that there is no standard and clearly validated procedure for models when the method of estimation is the ULS. We performed a significance test on the basis of the fitting function, which is equivalent to the well-known $\chi^{2}$ test. The test showed that the model with three factors is better than the model with two factors (fitting-function difference $=67.18, d f=2, p<.001$ ) . In a second step, considering the cross-loading problems from the PCA and the clinical considerations mentioned above, we tested two additional models. The first (Model $3 \mathrm{~F}-\mathrm{a})$ was the three-factor solution with Items 2 and 17 removed, and in the second (Model 3F-b), Item 16 was also

Table 1. Fit indices from ULS confirmatory factor analysis of the four models

\begin{tabular}{|c|c|c|c|c|c|}
\hline & AGFI & NFI & TLI & CFI & RMSEA \\
\hline Two-factor model & 0.990 & 0.971 & 0.978 & 0.981 & 0.095 \\
\hline Three-factor model & 0.991 & 0.976 & 0.983 & 0.986 & 0.084 \\
\hline $\begin{array}{l}\text { Three-factor model with Items } 2 \text { and } 17 \\
\text { removed (Model 3F-a) }\end{array}$ & 0.993 & 0.979 & 0.986 & 0.988 & 0.077 \\
\hline $\begin{array}{l}\text { Three-factor model with Items } 2,16 \text {, and } 17 \\
\text { removed (Model 3F-b) }\end{array}$ & 0.993 & 0.978 & 0.985 & 0.988 & 0.076 \\
\hline
\end{tabular}

Note. ULS: unweighted least squares; AGFI: adjusted goodness-of-fit index; NFI: normed-fit index; TLI: TuckerLewis index; CFI: comparative fit index; RMSEA: root mean square error of approximation. 
Table 2. Factor loadings for the three-factor solution from ULS with robust standard errors confirmatory factor analysis

\begin{tabular}{|c|c|c|c|c|}
\hline & Estimate & $S E$ & $Z$ value & $p(>|z|)$ \\
\hline \multicolumn{5}{|l|}{ Factor I (enhancement) } \\
\hline 1. To get entertained & 1.00 & & & \\
\hline 4. Because I like the feeling & 1.04 & 0.08 & 13.31 & $>.001$ \\
\hline 7. Because it's exciting & 1.12 & 0.09 & 12.77 & $>.001$ \\
\hline 9. For watching & 0.97 & 0.08 & 11.52 & $>.001$ \\
\hline 10. To get a "high" feeling & 0.97 & 0.09 & 10.29 & $>.001$ \\
\hline 11. For masturbation & 0.79 & 0.08 & 9.52 & $>.001$ \\
\hline 13. Simply because it's fun & 1.18 & 0.08 & 14.40 & $>.001$ \\
\hline \multicolumn{5}{|l|}{ Factor II (coping motives: escape) } \\
\hline 6. In order to forget my problems or worries & 1.00 & & & \\
\hline 12. Because it helps me when I'm depressed or nervous & 0.95 & 0.07 & 14.30 & $>.001$ \\
\hline 15. It comforts me when I'm in a bad mood & 1.01 & 0.07 & 14.18 & $>.001$ \\
\hline \multicolumn{5}{|l|}{ Factor III (social motives) } \\
\hline 3. To meet somebody & 1.00 & & & \\
\hline 5. Because I need to exchange with other people & 1.98 & 0.49 & 4.03 & $>.001$ \\
\hline 8. For being sociable and appreciated by others & 2.07 & 0.55 & 3.78 & $>.001$ \\
\hline 14. Because it makes a social gathering more enjoyable & 1.84 & 0.49 & 3.80 & $>.001$ \\
\hline \multicolumn{5}{|l|}{ Covariances } \\
\hline \multicolumn{5}{|l|}{ Enhancement with } \\
\hline Coping motives & 0.69 & 0.03 & 22.7 & $>.001$ \\
\hline Social motives & 0.25 & 0.02 & 13.3 & $>.001$ \\
\hline \multicolumn{5}{|l|}{ Coping motives } \\
\hline Social motives & 0.30 & 0.02 & 12.8 & $>.001$ \\
\hline
\end{tabular}

Note. SE: standard error; ULS: unweighted least squares.

removed. Fit indices of the three models with three factors are presented in the second part of Table 1. Although excellent fits were found except for the RMSEA for Model $3 \mathrm{~F}-\mathrm{a}$, it fit the data worse than the full model did, whereas Model 3F-b showed better fit on every index. Therefore, we removed Items 2, 16, and 17 from the questionnaire.

Table 2 shows the loadings of the three-factor solution with Items 2, 16, and 17 removed according to the above results. Every loading was significantly different from 0 . The estimated correlations between the three factors were significant.

In accordance with the GMQ factors, the three retained factors were enhancement (first factor), coping (second factor), and social motives (third factor).

\section{Reliability}

The internal consistency estimated by Cronbach's $\alpha$ for the three-factor solution (Model 3F-b) was about 0.81 [95\% confidence interval (CI): $0.79,0.83]$ and 0.88 [95\% CI: $0.86,0.91]$ for the enhancement factor; 0.79 [95\% CI: $0.76,0.81]$ and 0.86 [95\% CI: 0.83, 0.89] for the coping motives factor; and 0.74 [95\% CI: $0.71,0.77$ ] and 0.76 [95\% CI: $0.71,0.81]$ for the social motives factor in the first and the second samples, respectively. Moreover, the CR (Bacon, Sauer, \& Young, 1995) was performed because Cronbach's $\alpha$ is known to underestimate the true reliability in specific situations (Raykov, 1998). CR provides almost the same coefficients as Cronbach's $\alpha$ (enhancement: 0.81 and 0.89 ; coping motives: 0.82 and 0.86 ; and social motives: 0.73 and 0.79 in the first and the second samples, respectively). Cronbach's $\alpha$ and CR suggest good reliability.

\section{Correlations}

Moderate positive correlations were found between the SDI subscales and enhancement motives, whereas small correlations were found between these subscales and coping motives. Small correlations were found between social motives and the dyadic SDI subscale but not the solitary SDI (Table 3).

\section{DISCUSSION}

Despite a three-factor structure standing out in the previous studies on the GMQ (Stewart \& Zack, 2008) and the Drinking Motives Questionnaire (Cooper et al., 1992), we could not find such a well-defined structure by performing a PCA on the adapted 17-item version of the CysexMQ. In both the two- and the three-factor solutions, some items had high cross-loadings on more than one factor. In a second step, however, a CFA on a second sample suggested that a three-factor solution better fit the data.

Table 3. Spearman's correlations between CysexMQ and SDI subscales

\begin{tabular}{lccc}
\hline & $\begin{array}{c}\text { CysexMQ } \\
\text { enhancement }\end{array}$ & $\begin{array}{c}\text { CysexMQ } \\
\text { coping }\end{array}$ & $\begin{array}{c}\text { CysexMQ } \\
\text { social }\end{array}$ \\
\hline SDI dyadic & $.46^{* * *}$ & $.18^{* * *}$ & $.18^{* * *}$ \\
SDI solitary & $.54^{* * *}$ & $.18^{* * *}$ & .07 \\
\hline
\end{tabular}

Note. CysexMQ: Cybersex Motives Questionnaire; SDI: Sexual Desire Inventory.

$* * * p<.001$. 
To resolve the problem related to the items with crossloadings, we assessed different models with three factors without two or three of the problematic items. The best fit indices were obtained for a three-factor model without the three problematic items. The final CysexMQ was a 14-item scale.

The names of the three retained factors, enhancement, coping, and social motives, are similar to those proposed for the GMQ because of the partial similarity in types of motives. This result is consistent with those of previous studies that supported the involvement of social (Sumter et al., 2017), coping (Laier et al., 2015), and enhancement motives (Reid et al., 2011) in cybersex. However, several items differ in some ways from those of the GMQ, reflecting the specificities of cybersex behaviors.

All loadings were statistically significant and had about the same magnitude. The three factors were moderately correlated, except for enhancement and coping motives, for which the correlations were high. This finding is concordant with results from studies on the GMQ and can be explained by a possible role for such motives in emotion regulation (Devos et al., 2017; Wu, Tao, Tong, \& Cheung, 2011). These motives may play different roles in problem and non-problem cybersex use, as reported in studies on Internet gaming (Billieux et al., 2011; Zanetta Dauriat et al., 2011). As suggested by possible associations between behavioral addictions and mood disorders (Khazaal et al., 2016; Starcevic \& Khazaal, 2017; Strittmatter et al., 2015), further studies on the possible links between the CysexMQ, psychiatric symptoms, and problem cybersex use are warranted.

Both Cronbach's $\alpha$ and CR showed good internal consistency. Convergent validity was assessed using correlations with the SDI. Correlation levels were different across motives and dyadic and solitary sexual desire. Not surprisingly, there was no association between solitary desire and social motives. The strongest associations were found between the enhancement motives and the SDI subscales, which show the importance of such motives in cybersex use, in consistency with the enhancing and arousing effects of cybersex (Beutel et al., 2017; Reid et al., 2011). A correlation, albeit less strong, was also found between coping motives and the SDI subscales. Such motives are probably more important in subsamples of cybersex users who have anxious or avoidant attachment styles (Favez \& Tissot, 2016). Further studies assessing attachment styles in cybersex use and cybersex motives are warranted to explore this hypothesis.

The results of this study should be considered in light of several main limitations. First, recruitment through online advertising is associated with possible self-selection biases (Khazaal et al., 2014). Second, as commonly reported in online studies and surveys (Fleming et al., 2016; Hochheimer et al., 2016), a substantial part of the initial sample dropped out (395 of 640 completed the study). Third, the questionnaire was generated by adapting the GMQ to cybersex. As described earlier, the adaptation was based on previous studies in the field, on clinical observations, and on the authors' consensus. We cannot exclude the possibility that other motives were involved in the behavior.
However, the CysexMQ seems to have captured at least part of the main motives involved in cybersex, as shown by the psychometric analyses and the correlations with the SDI subscales.

\section{CONCLUSIONS}

This study confirmed the important involvement of enhancement (i.e., enhancement or sexual gratification), coping, and social motives in cybersex use in accordance with the results of previous studies (Brand et al., 2011; Laier \& Brand, 2014; Laier et al., 2015; Reid et al., 2011; Sumter et al., 2017). This finding suggests that the three-factor solution is clinically more relevant than the two-factor solution. Furthermore, this is the first study, to the best of our knowledge, to assess an adaptation of the GMQ to cybersex. Further studies on the links between the CysexMQ and cybersex use would be of interest for a better understanding of the role of motives in this behavior.

Funding sources: None.

Authors' contribution: YK, FB-D, and SR: study concept and design. EF, SR, and YK: statistical analysis and interpretation of data. TL, KJ, and YK: recruitment. EF, YK, KJ, TL, SR, and FB-D: redaction of the manuscript.

Conflict of interest: The authors declare no conflict of interest.

Acknowledgements: The authors would like to thank Barbara Every, ELS, of BioMedical Editor, for English language editing. They would also like to thank the participants involved in the study.

\section{REFERENCES}

Bacon, D. R., Sauer, P. L., \& Young, M. (1995). Composite reliability in structural equations modeling. Educational and Psychological Measurement, 55(3), 394-406. doi:10.1177/ 0013164495055003003

Bentler, P. M. (1990). Comparative fit indexes in structural models. Psychological Bulletin, 107(2), 238-246. doi:10.1037/00332909.107.2.238

Bentler, P. M., \& Bonnet, D. G. (1980). Significance tests and goodness of fit in the analysis of covariance structures. Psychological Bulletin, 88(3), 588-606. doi:10.1037/00332909.88.3.588

Beutel, M. E., Giralt, S., Wolfling, K., Stobel-Richter, Y., Subic-Wrana, C., Reiner, I., Tibubos, A. N., \& Brahler, E. (2017). Prevalence and determinants of online-sex use in the German population. PLoS One, 12(6), e 0176449. doi:10.1371/ journal.pone. 0176449

Billieux, J., Chanal, J., Khazaal, Y., Rochat, L., Gay, P., Zullino, D., \& Van der Linden, M. (2011). Psychological predictors of problematic involvement in massively multiplayer online 
role-playing games: Illustration in a sample of male cybercafe players. Psychopathology, 44(3), 165-171. doi:10.1159/ 000322525

Billieux, J., Van der Linden, M., Achab, S., Khazaal, Y., Paraskevopoulos, L., Zullino, D., \& Thorens, G. (2013). Why do you play World of Warcraft? An in-depth exploration of self-reported motivations to play online and in-game behaviours in the virtual world of Azeroth. Computers in Human Behavior, 29(1), 103-109. doi:10.1016/j.chb.2012.07.021

Bothe, B., Toth-Kiraly, I., Zsila, A., Griffiths, M. D., Demetrovics, Z., \& Orosz, G. (2018). The development of the Problematic Pornography Consumption Scale (PPCS). The Journal of Sex Research, 55(3), 395-406. doi:10.1080/00224499.2017. 1291798

Brand, M., Laier, C., Pawlikowski, M., Schachtle, U., Scholer, T., \& Altstotter-Gleich, C. (2011). Watching pornographic pictures on the Internet: Role of sexual arousal ratings and psychologicalpsychiatric symptoms for using Internet sex sites excessively. Cyberpsychology, Behavior, and Social Networking, 14(6), 371-377. doi:10.1089/cyber.2010.0222

Carli, V., Durkee, T., Wasserman, D., Hadlaczky, G., Despalins, R., Kramarz, E., Wasserman, C., Sarchiapone, M., Hoven, C. W., Brunner, R., \& Kaess, M. (2013). The association between pathological Internet use and comorbid psychopathology: A systematic review. Psychopathology, 46(1), 1-13. doi: $10.1159 / 000337971$

Carnes, P. J. (2001). Cybersex, courtship, and escalating arousal: Factors in addictive sexual desire. Sexual Addiction \& Compulsivity, 8(1), 45-78. doi:10.1080/10720160127560

Cattell, R. B. (1966). The scree test for the number of factors. Multivariate. Behavioral Research, 1(2), 245-276. doi:10.1207/s15327906mbr0102_10

Clarke, D., Tse, S., Abbott, M. W., Townsend, S., Kingi, P., \& Manaia, W. (2007). Reasons for starting and continuing gambling in a mixed ethnic community sample of pathological and non-problem gamblers. International Gambling Studies, 7(3), 299-313. doi:10.1080/14459790701601455

Cole, D. A. (1987). Utility of confirmatory factor analysis in test validation research. Journal of Consulting and Clinical Psychology, 55(4), 584-594. doi:10.1037/0022-006X.55. 4.584

Cooper, M. L., Russell, M., Skinner, J. B., \& Windle, M. (1992). Development and validation of a three-dimensional measure of drinking motives. Psychological Assessment, 4(2), 123-132. doi:10.1037/1040-3590.4.2.123

Cronbach, L. J., \& Meehl, P. E. (1985). Construct validity in psychological tests. Psychological Bulletin, 52(4), 281-302. doi: $10.1037 / \mathrm{h} 0040957$

Dechant, K., \& Ellery, M. (2011). The effect of including a monetary motive item on the Gambling Motives Questionnaire in a sample of moderate gamblers. Journal of Gambling Studies, 27(2), 331-344. doi:10.1007/s10899-0109197-x

Devos, G., Bouju, G., Burnay, J., Maurage, P., Grall-Bronnec, M., \& Billieux, J. (2017). Adaptation and validation of the Gambling Motives Questionnaire-Financial (GMQ-F) in a sample of French-speaking gamblers. International Gambling Studies, 17(1), 87-101. doi:10.1080/14459795.2016.1264080

Doring, N. M. (2009). The Internet's impact on sexuality: A critical review of 15 years of research. Computers in Human Behavior, 25, 1089-1101. doi:10.1016/j.chb.2009.04.003
Dufour, M., Brunelle, N., Tremblay, J., Leclerc, D., Cousineau, M. M., Khazaal, Y., Légaré, A. A., Rousseau, M., \& Berbiche, D. (2016). Gender difference in Internet use and Internet problems among Quebec high school students. Canadian Journal of Psychiatry, 61(10), 663-668. doi:10.1177/ 0706743716640755

Efron, B. (1987). The Jackknife, the bootstrap, and other resampling plans. Philadelphia, PA: Society for Industrial and Applied Mathematics.

Favez, N., \& Tissot, H. (2016). Attachment tendencies and sexual activities: The mediating role of representations of sex. Journal of Social and Personal Relationships, 14, 321-342. doi:10. 1177/0265407516658361

Fleming, T. M., de Beurs, D., Khazaal, Y., Gaggioli, A., Riva, G., Botella, C., Baños, R. M., Aschieri, F., Bavin, L. M., Kleiboer, A., Merry, S., Lau, H. M., \& Riper, H. (2016). Maximizing the impact of e-therapy and serious gaming: Time for a paradigm shift. Front Psychiatry, 7, 65. doi:10.3389/ fpsyt.2016.00065

Frangos, C. C., Frangos, C. C., \& Sotiropoulos, I. (2011). Problematic Internet use among Greek university students: An ordinal logistic regression with risk factors of negative psychological beliefs, pornographic sites, and online games. Cyberpsychology, Behavior, and Social Networking, 14(1-2), 51-58. doi:10.1089/cyber.2009.0306

Geisel, O., Panneck, P., Stickel, A., Schneider, M., \& Muller, C. A. (2015). Characteristics of social network gamers: Results of an online survey. Front Psychiatry, 6, 69. doi:10.3389/ fpsyt.2015.00069

Gmeiner, M., Price, J., \& Worley, M. (2015). A review of pornography use research: Methodology and results from four sources. Cyberpsychology: Journal of Psychosocial Research on Cyberspace, 9(4), article 4. doi:10.5817/CP2015-4-4

Grov, C., Gillespie, B. J., Royce, T., \& Lever, J. (2011). Perceived consequences of casual online sexual activities on heterosexual relationships: A U.S. online survey. Archives of Sexual Behavior, 40(2), 429-439. doi:10.1007/s10508-010-9598-z

Grubbs, J. B., Volk, F., Exline, J. J., \& Pargament, K. I. (2015). Internet pornography use: Perceived addiction, psychological distress, and the validation of a brief measure. Journal of Sex and Marital Therapy, 41(1), 83-106. doi:10.1080/ 0092623X.2013.842192

Harrison, D. A., \& McLaughlin, M. E. (1993). Cognitive processes in self-report responses: Tests of item context effects in work attitude measures. Journal of Applied Psychology, 78(1), 129-140. doi:10.1037/0021-9010.78.1.129

Hilgard, J., Engelhardt, C. R., \& Bartholow, B. D. (2013). Individual differences in motives, preferences, and pathology in video games: The gaming attitudes, motives, and experiences scales (GAMES). Frontiers in Psychology, 4, 608. doi:10.3389/fpsyg.2013.00608

Hochheimer, C. J., Sabo, R. T., Krist, A. H., Day, T., Cyrus, J., \& Woolf, S. H. (2016). Methods for evaluating respondent attrition in web-based surveys. Journal of Medical Internet Research, 18(11), e301. doi:10.2196/jmir.6342

Hu, L. T., \& Bentler, P. M. (1999). Cutoff criteria for fit indexes in covariance structure analysis: Conventional criteria versus new alternatives. Structural Equation Modeling, 6(1), 1-55. doi:10.1080/10705519909540118

Joreskog, K. G., \& Sorbom, D. (1996). LISREL 8: User's reference guide. Chicago, IL: Scientific Software International. 
Kafka, M. P. (2010). Hypersexual disorder: A proposed diagnosis for DSM-V. Archives of Sexual Behavior, 39(2), 377-400. doi:10.1007/s10508-009-9574-7

Khazaal, Y., Achab, S., Billieux, J., Thorens, G., Zullino, D., Dufour, M., \& Rothen, S. (2015). Factor structure of the Internet Addiction Test in online gamers and poker players. JMIR Mental Health, 2(2), e12. doi:10.2196/mental.3805

Khazaal, Y., Chatton, A., Achab, S., Monney, G., Thorens, G., Dufour, M., Zullino, D., \& Rothen, S. (2016). Internet gamblers differ on social variables: A latent class analysis. Journal of Gambling Studies, 33(3), 881-897. doi:10.1007/s10899016-9664-0

Khazaal, Y., Chatton, A., Horn, A., Achab, S., Thorens, G., Zullino, D., \& Billieux, J. (2012). French validation of the Compulsive Internet Use Scale (CIUS). The Psychiatric Quarterly, 83(4), 397-405. doi:10.1007/s11126-012-9210-x

Khazaal, Y., van Singer, M., Chatton, A., Achab, S., Zullino, D., Rothen, S., Khan, R., Billieux, J., \& Thorens, G. (2014). Does self-selection affect samples' representativeness in online surveys? An investigation in online video game research. Journal of Medical Internet Research, 16(7), e164. doi:10. 2196/jmir.2759

King, B. E., \& Allgeier, E. R. (2000). The Sexual Desire Inventory as a measure of sexual motivation in college students. Psychological Report, 86(1), 347-350. doi:10.2466/pr0.2000.86. 1.347

Kiraly, O., Urban, R., Griffiths, M. D., Agoston, C., Nagygyorgy, K., Kokonyei, G., \& Demetrovics, Z. (2015). The mediating effect of gaming motivation between psychiatric symptoms and problematic online gaming: An online survey. Journal of Medical Internet Research, 17(4), e88. doi:10.2196/jmir.3515

Kor, A., Zilcha-Mano, S., Fogel, Y. A., Mikulincer, M., Reid, R. C., \& Potenza, M. N. (2014). Psychometric development of the Problematic Pornography Use Scale. Addictive Behaviors, 39(5), 861-868. doi:10.1016/j.addbeh.2014.01.027

Kostyshak, S. (2015). Package "bootstrap". CRAN. Retrieved from https:/cran.r-project.org/web/packages/bootstrap/bootstrap.pdf

Kuss, D. J., Louws, J., \& Wiers, R. W. (2012). Online gaming addiction? Motives predict addictive play behavior in massively multiplayer online role-playing games. Cyberpsychology, Behavior, and Social Networking, 15(9), 480-485. doi:10. 1089/cyber.2012.0034

Laier, C., \& Brand, M. (2014). Empirical evidence and theoretical considerations on factors contributing to cybersex addiction from a cognitive-behavioral view. Sexual Addiction \& Compulsivity, 21(4), 305-321. doi:10.1080/10720162.2014.970722

Laier, C., Pawlikowski, M., Pekal, J., Schulte, F. P., \& Brand, M. (2013). Cybersex addiction: Experienced sexual arousal when watching pornography and not real-life sexual contacts makes the difference. Journal of Behavioral Addictions, 2(2), 100-107. doi:10.1556/JBA.2.2013.002

Laier, C., Pekal, J., \& Brand, M. (2015). Sexual excitability and dysfunctional coping determine cybersex addiction in homosexual males. Cyberpsychology, Behavior, and Social Networking, 18(10), 575-580. doi:10.1089/cyber.2015.0152

Li, C. H. (2016). Confirmatory factor analysis with ordinal data: Comparing robust maximum likelihood and diagonally weighted least squares. Behavior Research Methods, 48(3), 936-949. doi:10.3758/s13428-015-0619-7

Mark, K. P., Toland, M. D., Rosenkrantz, D. E., Brown-Stein, H. M., \& Hong, S.-H. (2018). Validation of the Sexual Desire
Inventory for lesbian, gay, bisexual, trans, and queer adults. Psychology of Sexual Orientation and Gender Diversity, 5(1), 122-128. doi:10.1037/sgd0000260

Moyano, N., Vallejo-Medina, P., \& Sierra, J. C. (2017). Sexual desire inventory: Two or three dimensions? Journal of Sex Research, 54(1), 105-116. doi:10.1080/00224499.2015.1109581

Ortega, V., Zubeidat, I., \& Sierra, J. C. (2006). Further examination of measurement properties of Spanish version of the Sexual Desire Inventory with undergraduates and adolescent students. Psychological Reports, 99(1), 147-165. doi:10.2466/pr0.99.1.147-165

Raykov, T. (1998). On the use of confirmatory factor analysis in personality research. Personality and Individual Differences, 24(2), 291-293. doi:10.1016/S0191-8869(97)00159-1

Reid, R. C., Li, D. S., Gilliland, R., Stein, J. A., \& Fong, T. (2011). Reliability, validity, and psychometric development of the Pornography Consumption Inventory in a sample of hypersexual men. Journal of Sex \& Marital Therapy, 37(5), 359-385. doi:10.1080/0092623X.2011.607047

Revelle, W. (2014). Package "psych". CRAN. Retrieved from http://cran.r-project.org/web/packages/psych/psych.pdf

Robinson, T. E., \& Berridge, K. C. (2008). Review. The incentive sensitization theory of addiction: Some current issues. Philosophical Transactions of the Royal Society of London. Series B, Biological Sciences, 363(1507), 3137-3146. doi:10.1098/ rstb.2008.0093

Ross, M. W., Mansson, S. A., \& Daneback, K. (2012). Prevalence, severity, and correlates of problematic sexual Internet use in Swedish men and women. Archives of Sexual Behavior, 41(2), 459-466. doi:10.1007/s10508-011-9762-0

Rosseel, Y. (2012). Lavaan: An R package for structural equation modeling. Journal of Statistical Software, 48(2), 1-36. doi:10.18637/jss.v048.i02

Schneeweiss, H., \& Mathes, H. (1995). Factor analysis and principal components. Journal of Multivariate Analysis, 55(1), 105-124. doi:10.1006/jmva.1995.1069

Spector, I. P., Carey, M. P., \& Steinberg, L. (1996). The Sexual Desire Inventory: Development, factor structure, and evidence of reliability. Journal of Sex \& Marital Therapy, 22(3), 175-190. doi:10.1080/00926239608414655

Starcevic, V., \& Khazaal, Y. (2017). Relationships between behavioural addictions and psychiatric disorders: What is known and what is yet to be learned? Front Psychiatry, 8, 53. doi:10.3389/fpsyt.2017.00053

Stewart, S. H., \& Zack, M. (2008). Development and psychometric evaluation of a three-dimensional Gambling Motives Questionnaire. Addiction, 103(7), 1110-1117. doi:10.1111/j.13600443.2008.02235. $\mathrm{x}$

Strittmatter, E., Kaess, M., Parzer, P., Fischer, G., Carli, V., Hoven, C. W., Wasserman, C., Sarchiapone, M., Durkee, T., Apter, A., Bobes, J., Brunner, R., Cosman, D., Sisask, M., Värnik, P., \& Wasserman, D. (2015). Pathological Internet use among adolescents: Comparing gamers and non-gamers. Psychiatry Research, 228(1), 128-135. doi:10.1016/j.psychres.2015.04.029

Sumter, S. R., Vandenbosch, L., \& Ligtenberg, L. (2017). Love me Tinder: Untangling emerging adults' motivations for using the dating application Tinder. Telematics and Informatics, 34(1), 67-78. doi:10.1016/j.tele.2016.04.009

Tsimtsiou, Z., Haidich, A. B., Kokkali, S., Dardavesis, T., Young, K. S., \& Arvanitidou, M. (2014). Greek version of the Internet Addiction Test: A validation study. The Psychiatric Quarterly, 85(2), 187-195. doi:10.1007/s11126-013-9282-2 
Tucker, L. R., \& Lewis, C. (1973). A reliability coefficient for maxiumum likelihood factor analysis. Psychometrika, 38(1), 1-10. doi:10.1007/BF02291170

Twohig, M. P., Crosby, J. M., \& Cox, J. M. (2009). Viewing Internet pornography: For whom is it problematic, how, and why? Sexual Addiction \& Compulsivity, 16(4), 253-266. doi:10.1080/10720160903300788

Velicer, W. F. (1976). Determining the number of components from the matrix of partial correlations. Psychometrika, 41(3), 321-327. doi:10.1007/BF02293557

Velicer, W. F., \& Jackson, D. N. (1990). Component analysis versus common factor analysis: Some issues in selecting an appropriate procedure. Multivariate Behavioral Research, 25(1), 1-28. doi:10.1207/s15327906mbr2501_1

Voon, V., Mole, T. B., Banca, P., Porter, L., Morris, L., Mitchell, S., Lapa, T. R., Karr, J., Harrison, N. A., Potenza, M. N., \& Irvine, M. (2014). Neural correlates of sexual cue reactivity in individuals with and without compulsive sexual behaviours. PLoS One, 9(7), e102419. doi:10.1371/journal. pone. 0102419
Wu, A., Tao, V., Tong, K.-K., \& Cheung, S. F. (2011). Psychometric evaluation of the inventory of Gambling Motives, Attitudes and Behaviours (GMAB) among Chinese gamblers. International Gambling Studies, 12(3), 331-347. doi:10.1080/ 14459795.2012.678273

Young, K. S. (2008). Internet sex addiction risk factors, stages of development, and treatment. American Behavioral Scientist, 52(1), 21-37. doi:10.1177/0002764208321339

Young, K. S., Griffin-Shelley, E., Cooper, A., O'mara, J., \& Buchanan, J. (2000). Online infidelity: A new dimension in couple relationships with implications for evaluation and treatment. Sexual Addiction \& Compulsivity: The Journal of Treatment and Prevention, 7(1-2), 59-74. doi:10.1080/ 10720160008400207

Zanetta Dauriat, F., Zermatten, A., Billieux, J., Thorens, G., Bondolfi, G., Zullino, D., \& Khazaal, Y. (2011). Motivations to play specifically predict excessive involvement in massively multiplayer online role-playing games: Evidence from an online survey. European Addiction Research, 17(4), 185-189. doi:10.1159/000326070 